UNDERGROUND MINING ENGINEERING 33 (2018) 53-60 $\quad$ UDK 62

UNIVERSITY OF BELGRADE - FACULTY OF MINING AND GEOLOGY

ISSN 03542904

Professional paper

\title{
SELECTING THE OPTIMAL DRILLING AND BLASTING DESIGN FOR UNDERGROUND EXCAVATIONS IN UNDERGROUND COPPER MINE "JAMA" BOR
}

\author{
Dejan Bogdanović ${ }^{1}$ and Goran Stojanović ${ }^{2}$
}

Received: September 21, 2018

Accepted: November 13, 2018

\begin{abstract}
Drilling and blasting operations are very important part of underground excavation design. They should be performed in accordance with some criteria, such as fragmentation, excavation stability and cost. In the paper are considered three drilling and blasting designs in order to reach the optimal one. To do so, all the criteria should be simultaneously considered in the analysis. For analysis is used Analytic Hierarchy Process - AHP method. Using AHP method, drilling and blasting patterns in underground copper mine "Jama" Bor are investigated and analysed. According to the obtained results, alternative 2 with contour drilling and blasting pattern was selected to be the best decision. Application of this alternative comparatively satisfies both fragmentation and excavation stability.
\end{abstract}

Keywords: drilling; blasting; underground excavations; AHP;

\section{INTRODUCTION}

Drilling and blasting operations in underground copper mine "Jama" Bor are performed for all types of underground excavations design. In those operations, producing a desired fragment size distribution (Michaux and Djordjevic, 2005) as well as the stability of underground excavations (Bogdanović, 1995) are considered to be the main objectives satisfying the overall mine economics.

Since the selection of the optimal drilling and blasting design is very crucial to satisfying the aforesaid criteria, many parameters need to be considered such as hole diameter, delay time, specific charge, stemming, physic-mechanical properties and discontinuities (Monjezi et al., 2012). Variation in each one of these parameters could affect the efficiency of the whole drilling and blasting process (Zhu et al. 2007, 2008; Thornton et al. 2002).

In this paper, AHP method, a branch of multi-criteria decision making (MCDM) methods, is utilized to select the optimal operated drilling and blasting design. This

\footnotetext{
${ }^{1}$ University of Belgrade - Technical faculty in Bor

${ }^{2}$ University "Union-Nikola Tesla" Belgrade - Faculty of applied sciences

Emails: dbogdanovic@ @tfbor.bg.ac.rs; stojanovicg11@yahoo.com;
} 
methods is selected because it consider all of the relevant parameters and can convert the qualitative parameters into the quantitative ones.

\section{DRILLING AND BLASTING PATTERNS (ALTERNATIVES)}

In underground copper mine "Jama" Bor drilling and blasting operations are used for decades. Today, these operations are performed in a modern way, using modern equipment and new explosives and devices.

In this paper the low vaulted ("flattened arch" roof) with vertical sidewalls excavations are considered with cross-sections of $12,50 \mathrm{~m}^{2}(4 \mathrm{~m} \times 3,5 \mathrm{~m})-$. The drilling diameter is $42 \mathrm{~mm}$, and drillhole length is $3,0 \mathrm{~m}$. AMONAL explosive is used for blasting. Ignition is performed by electro detonators. Stemming length is from $0,8 \mathrm{~m}$ to $1,6 \mathrm{~m}$. The rock is made of the andesite.

There are three basic drilling and blasting patterns in use: "classic", contour and irregular.

The classic pattern (alternative 1) is defined by appropriate calculations in technical documentation. Number of drillholes is 35 to 40 . Total amount of explosives is from $70 \mathrm{~kg}$ to $75 \mathrm{~kg}$. Specific charge is from $2,1 \mathrm{~kg} / \mathrm{m}^{3}$ to $2,2 \mathrm{~kg} / \mathrm{m}^{3}$. The cut is wedge-shaped 4 holes each loaded with $2 \mathrm{~kg}$ of explosives. There are 16 to 21 stoping holes loaded with 1,5 to $2 \mathrm{~kg}$ of explosives and 15 side holes ( 6 roof holes loaded with $1,5 \mathrm{~kg}$ of explosives, 4 wall holes and 5 floor holes loaded with 1,5 to $2 \mathrm{~kg}$ of explosives).

The contour drilling and blasting pattern (alternative 2) is similar to classic pattern, but there is paid the attention to the roof holes. They are design to prevent smooth blasting. Number of drillholes is 35 . Total amount of explosives is $65 \mathrm{~kg}$. Specific charge is from $1,9 \mathrm{~kg} / \mathrm{m}^{3}$. The cut is wedge-shaped -4 holes each loaded with $2 \mathrm{~kg}$ of explosives. There are 16 stoping holes loaded with 1,5 to $2 \mathrm{~kg}$ of explosives and 15 side holes ( 6 roof holes loaded with $1 \mathrm{~kg}$ of explosives, 4 wall holes and 5 floor holes loaded with 1,5 to $2 \mathrm{~kg}$ of explosives).

The irregular pattern (alternative 3) is a result of the technically defective work by miners. Number of drill holes differ and it is often less then 35, in some cases about 25 . Total amount of explosives also can fall to $35 \mathrm{~kg}$. The only regular thing is cut - wedgeshaped -4 holes each loaded with $2 \mathrm{~kg}$ of explosives. The number of other holes differ and the explosive amount per hole is from 1 to $2 \mathrm{~kg}$. There is no stemming in holes. 


\section{DRILLING AND BLASTING CRITERIA}

The criteria include the most important parameters drilling and blasting patterns ranking.

Rock fragmentation (criteria 1) after blasting depends on the following parameters: drill hole diameter, stemming, explosives, delay timing, rock mass type, etc. Adequate rock fragmentation is very important for efficient load and transport operation. Also, there is no need for secondary blasting of outsized rocks.

Excavation stability (criteria 2 ) is very important parameter regarding to work safety and efficient exploitation of the ore body. Besides the applied drilling and blasting pattern, it depends on many others parameters such as geological structures and mechanical properties of rock masses and discontinuities (Xing et al., 2017). Torbica and Lapcevic (2014) also point to corelation between blasted rock fragmentation the blast damages zones around underground excavations.

Cost (criteria 3) of driling and blasting patterns depends on applied technology of drilling, number of drillholes, applied explosives and its the total amount, number of workers, etc. There is relation between drilling and blasting cost and fragmentation of rock. Higher drilling and blasting cost led to better fragmentation of rock, but that decrease load and transport cost, crushing cost etc.

\section{AHP METHOD}

The Analytic Hierarchy Process (AHP) is developed by Saaty (1980) to support multicriteria decision making. It is a quantitative technique that analyzes the complex decision making problem, To do so, AHP develops a multi-dimensional hierarchical structure of objectives, criteria and alternatives. Then, AHP calculates the strength (weight coefficient) of each criteria. Next, it compares the alternatives with respect to the criteria and finally ranks the alternatives.

Accordingly, AHP uses a comparison matrix to assess the impact of each criteria and comparison of alternatives in relation to the each criteria. Comparison of criteria and alternatives is done on the basis of assessment by marks from 1 to 9 - Table 1.

Table 1 Pair-wise Comparison Scale for AHP preference

\begin{tabular}{lc}
\hline Verbal Judgement & Numerical Rating \\
\hline Equally preferred & 1 \\
Moderately preferred & 3 \\
Strongly preferred & 5 \\
Very strongly preferred & 7 \\
Extremely preferred & 9 \\
$2,4,6$ and 8 are intermediate values \\
\hline
\end{tabular}


Based on a comparison of the decision elements, the application of proper assessment leads to the final rank of alternatives.

\section{RESULTS OF ANALYSIS}

In order to determine the optimal driling and blasting pattern, the measures has conducted using the three-stage qualitative scale: high (best results), medium (satisfactory results) and low (unsatisfactory results). Table 2 shows the practical results of each pattern.

After defining alternatives (drilling and blasting patterns) and the criteria, they are being scored and ranked by AHP method, based on results given in Table 2. In addition, the Criterium DecisionPlus software was used for calculations.

Table 2 Practical results of drilling and blasting patterns

\begin{tabular}{cccc}
\hline \multirow{2}{*}{ Alternative } & \multicolumn{3}{c}{ Criteria } \\
\cline { 2 - 4 } & Fragmentation & $\begin{array}{c}\text { Excavation } \\
\text { stability }\end{array}$ & $\begin{array}{c}\text { Drilling and blasting } \\
\text { cost }\end{array}$ \\
\hline 1 & High & Medium & Medium \\
2 & Medium & High & Medium \\
3 & Low & Low & High \\
\hline
\end{tabular}

Firstly, the multi-dimensional hierarchical structure of the objective, criteria and alternatives are defined - Figure 1. After that, the coefficients of criteria weights are determined based on the scale of comparison given in Table 1. The results of comparison are shown in Table 3 and Table 4.

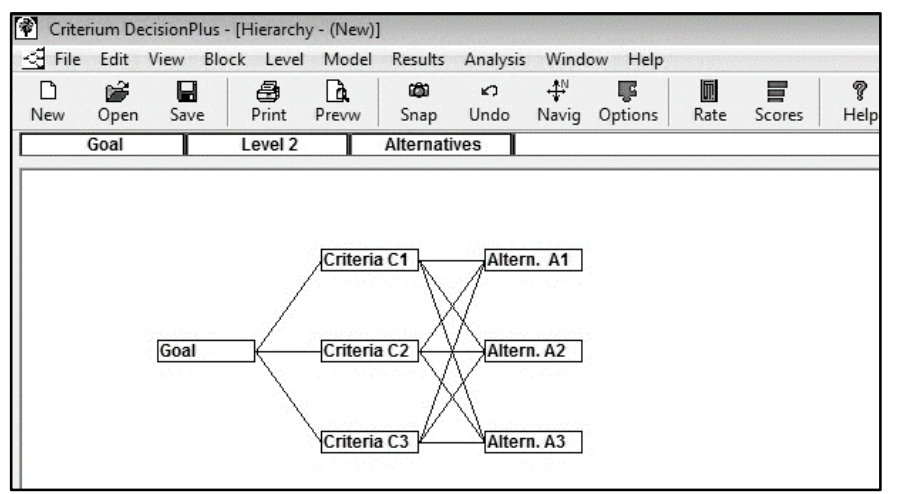

Figure 1 Hierarchical decision structure (Criterium DecisionPlus softver) 
Selecting the optimal drilling and blasting design...

Table 3 Defining of criteria weights

\begin{tabular}{cccc}
\hline Criteria & $\mathrm{C} 1$ & $\mathrm{C} 2$ & $\mathrm{C} 3$ \\
\hline $\mathrm{C} 1$ & 1 & $1 / 3$ & $1 / 4$ \\
$\mathrm{C} 2$ & & 1 & 2 \\
$\mathrm{C} 3$ & & & 1 \\
\hline
\end{tabular}

Table 4 The results of criteria weights

\begin{tabular}{lccc}
\hline Criteria & C1 & C2 & C3 \\
\hline Criteria weights & 0,124 & 0,517 & 0,359 \\
Coeff. of consistency & & $0,093<0,1$ & \\
\hline
\end{tabular}

In the next step, the comparison of the alternatives in relation to all three criteria is done - Tables 5-7.

Finally, the results of ranking are obtained - Table 8 . The results indicate that the optimal drilling and blasting pattern is an alternative A2 (contour drilling and blasting pattern). In the second place is an alternative A1 (classic drilling and blasting pattern) and in the third place is an alternative A3 (irregular drilling and blasting pattern).

Table 5 Alterntives comparison in relation to criteria $\mathrm{C} 1$

\begin{tabular}{cccc}
\hline Alternatives & A1 & A2 & A3 \\
\hline A1 & 1 & 3 & 7 \\
A2 & & 1 & 6 \\
A3 & & $0,086<0,1$ & 1 \\
Coeff. of consistency & & & \\
\hline
\end{tabular}

Table 6 Alterntives comparison in relation to criteria C2

\begin{tabular}{cccc}
\hline Alternatives & A1 & A2 & A3 \\
\hline A1 & 1 & $1 / 3$ & 4 \\
A2 & & 1 & 6 \\
A3 & & $0,046<0,1$ & 1 \\
Coeff. of consistency & & \\
\hline
\end{tabular}


Table 7 Alterntives comparison in relation to criteria C3

\begin{tabular}{cccc}
\hline Alternatives & A1 & A2 & A3 \\
\hline A1 & 1 & 2 & $1 / 2$ \\
A2 & & 1 & $1 / 3$ \\
A3 & & $0,008<0,1$ & 1 \\
Coeff. of consistency & & & \\
\hline
\end{tabular}

Table 8 The final rank of the alternatives

\begin{tabular}{ccc}
\hline No. & Drilling and blasting pattern & Result \\
\hline 1. & A2 (The contour drilling and blasting pattern) & 0,428 \\
2. & A1 (The classic drilling and blasting pattern) & 0.326 \\
3. & A3 (The irregular drilling and blasting pattern) & 0.246 \\
\hline
\end{tabular}

\section{THE ANALYSIS OF OBTAINED RESULTS}

When analyzing the impact of the criteria on the alternatives ranking it is started from the most influential criteria $2-$ excavation stability. It points to the safety and efficient exploitation.

In second place is the criteria 3 - the drilling and blasting cost. This is a criteria that takes into account the total cost of drilling and blasting and it is contradictory to other criteria.

In third place is the criteria 1 - fragmentation of rock.

In the analysis of the final rank of alternatives (drilling and blasting patterns) it is started from the best one. This is alternative A2 (contour drilling and blasting). Its weight coefficient is 0,428 meaninig that it meets $42.8 \%$ of the requirements of the criteria. First of all, this pattern provides good rock fragmentation and best excavation stability.

On the second palce is alternative 1 - classic drilling and blasting pattern. It is most often applied in underground copper mine "Jama" Bor. It provides best rock fragmentation, good excavation stability, but with higher cost compared with other alternatives. It meets $32,6 \%$ of the requirements of the criteria.

On the last place is alternative 3 (irregular drilling and blasting pattern). This alternative should no longer be applied. It is the best in terms of cost, becouse the small volume drilling and consumption of explosives, but with bed results in aspect of fragmentation and stability. Its weight coefficient is 0,246 . The reason is that the research found that its deviations are lower in relation to the projected solutions, thereby reducing its negative effects in relation to the other two alternatives. 


\section{CONCLUSION}

In this paper is applied multicriteria decision method for ranking of drilling and blasting patterns in underground copper mine "Jama" Bor. Drilling and blasting pattern significantly and adversely affect the operation of the mine. It is analyzed three types of drilling and blasting patterns - classic (alternative A1), contour (alternative 2) and irregular (alternative A3). It is also discussesed three criterioa for ranking - rock deragmentation (criteria $\mathrm{C} 1$ ), excavation stability (criteria $\mathrm{C} 2$ ) and cost (criteria $\mathrm{C} 3$ ).

Ranking of drilling and blasting patterns is carried out using the AHP method.

Based on the obtained results by AHP method, it is identified the optimal solution, which is alternative A2 (contour drilling and blasting pattern). The most influential criteria for ranking the patterns is the criteria $\mathrm{C} 2$ (excavation stability).

\section{REFERENCES}

BOGDANOVIĆ D. (1995) Application of contour blasting at the underground excavations in the ore body "Tilva Ros" in Bor mine. In:1th Yugoslav Simposium with International Participation "Drilling and Blasting". Belgrade: Mining and Geological Faculty, pp. 236-240.

MICHAUX, S. and DJORDJEVIC, N. (2005) Influence of explosive energy on the strength of the rock fragments and SAG mill throughput, Minerals Engineering, 18, pp. 439-448.

MONJEZI, M., Dehghani, H., Singh, T.N., Sayadi, A.R. and Gholinejad, A. (2012) Application of TOPSIS method for selecting the most appropriate blast design. Arabian Journal of Geosciences, 5, pp. 95-101.

SAATY, T.L. (1980) The Analytical Hierarchy Process. New York; McGraw-Hill.

THORNTON, D, KANCHIBOLTA, S,S, and BRUNTON, I. (2002) Modelling the impact and blast design variation on blast fragmentation. International Journal of Blasting Fragmentation, 6(2), pp 169-188.

TORBICA, S. and LAPCEVIC, V. (2014) Model for estimating blasted rock fragmentation. In: Proceedings of 14th SGEM GeoConference on Science and Technologies In Geology, Exploration and Mining. Albena, June 19-25. Albena: SGEM: Surveying Geology \& mining Ecology Management, pp. 379-386. 
XING, Y., KULATILAKE, P. H. S. W. and SANDBAK L. A.(2017) Rock Mass Stability Investigation Around Tunnels in an Underground Mine in USA. Geotechnical and Geological Engineering, 35(1), pp. 45-67.

ZHU, Z., MOHANTY, B. and XIE, H. (2007) Numerical investigation of blastinginduced crack initiation and propagation in rocks. International Journal of Rock Mechanics and Mining Sciences, 44, pp.412-424.

ZHU, Z., XIE, H. and MOHANTY, B. (2008) Numerical investigation of blasting induced damage in cylindrical rocks. International Journal of Rock Mechanics and Mining Sciences, 44, pp.111-121. 